\title{
Leaning on the Ethical Crutch: A Critique of Codes of Ethics
}

\author{
By Jathan Sadowski ${ }^{1}$
}

IEEE Technology and Society Magazine, Vol. 33, No. 4, p. 44-47, 72. (December 2014)

\section{Reasons for Professional Codes of Ethics}

What's a profession without a code of ethics? Being a legitimate profession almost requires drafting a code and, at least nominally, making members follow it. Codes of ethics (henceforth "codes") exist for a number of reasons - many of which can vary widely from profession to profession - but above all they are a form of codified selfregulation. Jamal and Bowie [12], in their conceptual framework for creating a meaningful code, classify three provisions that professional codes are meant to address:

1. "Provisions that address problems of moral hazard." There is often an asymmetry of knowledge between professionals and their clients. The asymmetry provides numerous opportunities for professionals to take advantage of their client or the general public by exploiting their lack of expertise. Codes can prohibit such actions.

2. "Provisions that provide norms of professional courtesy." Professions might see a need to place restrictions on the way that members act towards each other. In general, codes can prohibit members from lying, cheating, stealing, or acting unfairly towards each other.

3. "Provisions that define the public interest." Here the code lays out any obligations a professional has towards the public at large. Now, what that means will change amongst professions - it can be ambiguous or precise, and everywhere in between.

Different professions place more weight on certain provisional categories over others: some focus on legal liability, loyalty to clients, and the profession's reputation; some try to ensure coordination and civility among members; and some direct attention towards social responsibility and service. Codes change over time, but they're often obdurate documents. Of course there might be incremental revisions, additions, and deletions to the code, but rarely does a profession's focus or purpose change.

Historically, for instance, "the early ethics codes in professional engineering — such as those formulated in 1912 by the American Institute of Electrical Engineers (later to become the Institute of Electrical and Electronic Engineers) and in 1914 by the American Society of Civil Engineers (ASCE) - defined the primary duty of the engineer to be of service as a 'faithful agent or trustee' of an employing company" [16]. Arguably, five out

${ }^{1}$ Consortium for Science, Policy \& Outcomes, Arizona State University, Tempe, AZ, USA. 
of six Fundamental Canons in the current code for the National Society of Professional Engineer (NSPE) fall under the provision of addressing moral hazards and legal liability. ${ }^{2}$

Many scholars argue that codes are necessary for providing professions with a coherent mission. Bullock and Panicker [1] conducted a comparative analysis of almost 45 codes across a wide range of scientific and engineering associations in order to determine, both, which aspects remain constant and which themes are unique to certain fields. They explain that, across the professions, codes are broadly constructed to serve "the function of creating a common set of standards that define norms of behavior for professionals within a domain or discipline, thus, safeguarding both the integrity as well as the reputation of the discipline." Other scholars believe that codes are necessary for setting up constraints that prevent "the self-interest of individual [members], or even their selfless devotion to their employer," from harming everybody else [8].

\section{Contra-Codes}

While codes can be beneficial, I will argue that when we scratch below the surface there are many problems at their root. In terms of efficacy, codes can serve as a form of ethical window dressing, rather than effective rules for behavior. But even more that, codes can degrade the meaning behind being a good person who acts ethically for the right reasons.

I do not go so far to claim that, "The Urmythos from which all of the myths in the professional mythology spring is that professions are oriented to the service of humanity" [13]. There are obvious connections we can draw between modern professions and the guilds of old. It's disingenuous, though, to think that professions are deviously selfinterested-like the guilds that were set up to protect monopolies and secure economic and political power - to the point where codes are intentionally created as tools of deceit. Instead, one problem with codes resides in the fact that they receive so little educational attention and professional support that they become ineffective. In this case, I will use engineering ethics as an illustrative example - and, admittedly, the focus will largely be in a U.S. context - however, my argument is not necessarily limited to this specific profession.

Engineering education has only recently begun to take seriously the imperative of incorporating ethical training into the standard curricula for engineers. Although, it is easy to chalk up these pedagogical shifts to, at worst, a form of lip service or, at best, ambiguous endeavors that do little to actually enhance engineers' ethical capabilities [cf. 14]. Moreover, as philosopher of technology Langdon Winner [20] laments, the overemphasis on case studies and individually based "microethical" dilemmas do not prepare engineers for confronting the larger political and moral issues related to how technological systems are built and integrated into society.

"When [survey] results are normalized to account for number of graduates per institution, nearly $80 \%$ of engineering graduates attend schools that do not have an ethics-related

${ }^{2}$ The NSPE code can be found online here: <http://www.nspe.org/Ethics/CodeofEthics/index.html> 
course requirement for all students" [9]. Even if ethics pedagogies are carefully planned and implemented, these dismal statistics show that only a minority of engineers is exposed to them.

Moving beyond the education phase, when it comes time for professional engineers to put their ethical training to use, there is little support to brace them against negative reactions and consequences. Engineers who have followed the relevant codes - such as by whistleblowing or refusing to participate in unethical practices - often must face "demotions, firings, blacklisting, and even threats to life and limb" [10]. Without institutional support, say, from a professional society, an ethical engineer has little incentive to do the right thing without taking on the heavy burden of economic or physical risk. Indeed, the lack of ethics support is largely a consequence of the increasing corporate influence in professional engineering societies [10].

Concerns about the efficacy of codes can be addressed through efforts such as implementing widespread ethics education and developing robust institutional support. However, there are deeper issues with how codes as such change the moral landscapechanges that can be detrimental and ought not be ignored.

If professionals actually do follow the relevant code then they can checkmark the box for ethics, right? It should be no surprise that an algorithmic form of ethics can't possibly account for all the ethical dilemmas, both large and small, that fall outside of archetypal case studies and principles. Even then, "codes are presented as sufficient to handle the complex conflicts of duty which constitute real ethical debate" [6]. But, what we must recognize is that codes embody and propagate certain value-laden visions of a saintly professional - and thus they neglect the messy, dynamic, and complex realities of both people and the world [cf. 18][19]. Relying on ethical choices that are made "by the book" - even assuming an in-depth knowledge and recall of the code's provisionsleaves much to be desired as far as understanding tricky situations and tradeoffs go.

Proponents of codes attempt to head-off this critique by arguing that interpretation is a central aspect of using code - naturally, professionals interpret provisions first and then apply the spirit, if not the letter, of a code to a situation [4][5]. After all, many codes contain principles that are vague in their overarching decrees - such as the NSPE's first Fundamental Canon: "Hold paramount the safety, health, and welfare of the public"and hence interpretation is necessary. What these arguments miss is that interpretation is, in itself, a learned skill. People do not a priori possess the moral reasoning abilities to interpret principles and provisions so they can be applied in an ethical manner. It's not clear that professionals, even when they are trained in their respective codes, are also trained in the intricacies of interpreting those codes.

What's more, emphasizing codes results in conceptual consequences for what it means to be counted as an ethical professional. To quote ethicist Bob Brecher [2] at length:

"Codes reflect exactly the ambivalence of professionalization itself: their function is at one and the same time to hold professionals accountable and to protect them 
from moral accountability. Put crudely, professional ethics instrumentalize moral concern; and in doing so, both take morality out of the picture and depoliticize the object of what might have been moral concern.... whether or not a nurse is working 'ethically' all too easily becomes a matter of checking, and checking off, against a list of rules, while the rules themselves remain morally and politically unexamined."

Following Brecher, codes shape ethics into an instrumental application - just another tool, among many, in the engineer's box - to be referred to (or not) in the case of a discrete event. Extreme cases aside, if a professional follows the appropriate code then she has performed her duty and is absolved of liability. Codes do not encourage people to understand ethics as both something that courses through all aspects of life and as a key part of being a "good" person. Instead, ethics is degraded into that which fits in a code and can be marked as completed or not; thus, succumbing to the technocratic specter that always threatens to possess the engineering worldview [17].

Codes are also inherently conservative constructs that embody and extend the values of their creators. The code's mandates - which are the mandates of the code's framerspersist over time as a relatively stable and wide-ranging form of influence [cf. 11]. Changing codes is not a simple task. Even if a professional does decide to critically reflect on the code's principles and finds that they are insufficient, outdated, or otherwise wanting, it's unlikely that she will be able effect change — at least not without some form of sustained collective action.

A recent study [3] paints an even worse picture: due to an engrained "culture of disengagement" engineering students' concerns about public welfare - based on four categories of "professional/ethical responsibilities, understanding the consequences of technology, understanding how people use machines, and social consciousness"actually decline during the interim years of starting college, graduating, and becoming an employed professional. In other words, these results indicate that the further one integrates into the engineering culture, the less one is concerned about the very aspects of public welfare that codes are ostensibly supposed to guarantee. It appears that codes are not a strong enough ethical crutch, rather they are too easily ignored or instrumentalized.

\section{An Alternative to Codes}

Instead of relying on codes, professionals should embrace an ethic that builds a capacity for reflexive moral reasoning, nurtures self-development, and recognizes that socioethical engagement is an ongoing, constant process. "[M]orality should not be legislated in the profession[s] ... any more than it can be in our everyday lives" [15].

C.E. Harris [7] presents a clear, robust theoretical argument for approaching professional ethics through a lens of virtue ethics, rather than a code-based foundation. "First, rules cannot adequately account for the place of discretion, judgment, and background knowledge in meeting some professional obligations," Harris argues. "A second reason 
for the inadequacy of rules is that there is an internal, motivational, and often idealistic element present in professional life that cannot adequately be accounted for by rules" [7].

To address these limitations, Harris lays out the tenants of virtue ethics and their specific relevance to an engineering and technological context. His arguments, though, are not strictly limited to engineering - the theory is easily applicable to professions, in general. In short, virtue ethics as related to professionalism involves five aspects: 1) virtue is a wide-ranging character trait involving multiple characteristics; 2) gaining satisfaction from adhering to virtues; 3 ) knowing how to correctly make moral decisions at the right time and place; 4) nurturing and developing excellence in both technical and nontechnical virtues; and 5) "construct a professional virtue portrait of the "good engineer" [7].

Focusing on virtue ethics education is better overall for professionals and the profession. Through virtue ethics, professionals gain a reflexive self-understanding and hone their moral reasoning capacities, which can be flexibly and critically applied throughout their life - without having to rely on reference to a limited code. The profession as a whole gains by building a reputation of having genuinely good and well-rounded members.

There are, of course, limitations to using a virtue approach instead of relying on a code. Foremost, teaching virtue ethics is not a straightforward endeavor. Pedagogies that explicitly try to build the students' moral capacities often require more educational resources, both in terms of quality and quantity of instruction [e.g. 18]. Without dedicating already scarce resources to emphasizing ethics students may walk out of their training with less moral knowledge than if a professor had relied on a ready-made code. Additionally, without a code there is not a clear metric for ethical accountabilitythough, nor is there a solid shield for people to hide behind - which can make external judgments difficult. This can be detrimental for times when one or many members of a profession are guilty of negligence since there wouldn't be any explicitly stated duties they had an obligation to follow.

There is still much work that needs to be done in further developing theories and practices of a professional ethic centered on virtue and character. Yet, this should not deter - but instead reinvigorate - the work of establishing alternatives that actively address the varied pitfalls of codes. Although virtue ethics as an alternative to codes is, to be sure, more difficult to implement, the benefits far outweigh the costs and risks. If the decision is between saving time, effort, and other resources in order to provide professionals with a basic level of ethical capabilities or to value and recognize the importance of a well-developed moral capacity — the choice should be obvious.

\section{References}

[1] M. Bullock and S. Panicker, "Ethics for All: Differences Across Scientific Society Codes," Science and Engineering Ethics, vol. 9, no. 2, pp. 159-170, April 2003. 
[2] B. Brecher, "The Politics of Professional Ethics," The Journal of Clinical Evaluation in Practice, vol. 16, no. 2, pp. 351-355, April 2010.

[3] E.A. Cech, "Culture of Disengagement in Engineering Education?" Science, Technology, \& Human Values vol. 39, no. 1, pp. 42-72, January 2014.

[4] M. Davis, "Professional Responsibility: Just Following the Rules?" Business and Professional Ethics Journal, vol. 18, no. 1, pp. 65-87, Spring 1999.

[5] M. Davis, "Three Myths About Codes of Engineering Ethics," IEEE Technology and Society Magazine, vol. 20, no. 3, pp. 8-14, 22, Fall 2001.

[6] J. Fawkes, "Saints and Sinners: Competing Identities in Public Relations Ethics," Public Relations Review, vol. 38, no. 5, pp. 865-872, December 2012.

[7] C.E. Harris, "The Good Engineer: Giving Virtue Its Due in Engineering Ethics," Science and Engineering Ethics, vol. 14, no. 2, pp. 153-164, June 2008.

[8] M. Harris, "Thinking Like an Engineer: The Place of a Code of Ethics in the Practice of a Profession," Philosophy \& Public Affairs, vol. 20, no. 2, pp. 150-167, Spring 1991.

[9] J.R. Herkert, "Engineering Ethics Education in the USA: Content, Pedagogy and Curriculum," European Journal of Engineering Education, vol. 25, no. 4, pp. 303-313, Fall 2000.

[10] J.R. Herkert, "Future Directions in Engineering Ethics Research: Microethics, Macroethics and the Role of Professional Societies," Science and Engineering Ethics, vol. 7, no. 3, pp. 403-414, July 2001.

[11] L.D. Introna, "The Enframing of Code: Agency, Originality and the Plagiarist," Theory, Culture \& Society, vol. 28, no. 6, pp. 113-141, November 2011.

[12] K. Jamal and N.E. Bowie, "Theoretical Considerations for a Meaningful Code of Professional Ethics," Journal of Business Ethics, vol. 14, no. 9, pp. 703-714, September 1995.

[13] J. Kultgen, Ethics and Professionalism. Philadelphia, PA: University of Philadelphia Press, 1988.

[14] J. Ladd, "The Quest for a Code of Professional Ethics: an Intellectual and Moral Confusion," in AAAS Professional Ethics Project: Professional Ethics Activities in the Scientific and Engineering Societies, R. Chalk, M.S. Frankel, and S. B. Chafer, Eds. Washington, DC: AAAS, 1980, pp. 154-159.

[15] H.C. Luegenbiehl, "Codes of Ethics and the Moral Education of Engineers," Business \& Professional Ethics Journal, vol. 2 no. 4, pp. 41-61, Summer 1983. 
[16] C. Mitcham, "Engineering Design Research and Social Responsibility," in Technology and Values, K. Shrader-Frechette and L. Westra, Eds. Lanham, MD: Rowman and Littlefield, 1994, pp. 261-278.

[17] J. Sadowski and E. Selinger, "Creating a Taxonomic Tool for Technocracy and Applying it to Silicon Valley," Technology in Society vol. 38, pp. 161-168, August 2014.

[18] J. Sadowski, et al., "An Experiential, Game-Theoretic Pedagogy for Sustainability Ethics." Science and Engineering Ethics, vol. 19, no. 3, pp. 1323-1339, September 2013.

[19] J. Sadowski, et al., "Intergroup Cooperation in Common Pool Resource Dilemmas," Science and Engineering Ethics, DOI: 10.1007/s11948-014-9575-3, in press.

[20] L. Winner, "Engineering Ethics and Political Imagination," in Broad and Narrow Interpretations of Philosophy of Technology: Philosophy and Technology, P. Durbin, Ed. Boston, MA: Kluwer, 1990, pp. 53-64. 